\title{
POLÍTICAS FISCAIS COMO INSTRUMENTO DE REDUÇÃO DA DESIGUALDADE SOCIAL
}

\author{
Elisângela Aparecida de Medeiros ${ }^{31}$ \\ Marisa Rossignoli ${ }^{32}$
}

Recebido em: 22/11/2017

Aprovado em: 24/05/2018

\begin{abstract}
RESUMO
O presente artigo analisa o importante papel das políticas fiscais como um instrumento de redução das desigualdades sociais, demonstrando, em um primeiro momento, o modelo de produção capitalista e os desafios do Estado democrático de direito, vez que, através de políticas fiscais, o Estado, atua a serviço do desenvolvimento social e econômico. $\mathrm{O}$ estudo busca refletir sobre a economia de mercado no mundo globalizado, considerando seus pontos positivos e negativos e evidenciando a importância do modo de produção capitalista para o modelo econômico atual. Em um segundo momento, aborda, como pressuposto das atividades estatais, o desenvolvimento da política social através das políticas monetárias e fiscais, como uma obrigação e dever para com a sociedade, com o escopo de reduzir as desigualdades sociais, respeitando a coletividade, contribuindo efetivamente no desenvolvimento nacional. Por derradeiro, como resultado desse estudo, chegou-se à conclusão que através da implementação de políticas fiscais, por meio da tributação, o Estado ao equilibrar às receitas e despesas através do planejamento orçamentário, têm compromisso complementar às políticas do Estado, uma vez que as receitas lucrativas e ações sociais não são contrárias, o que representa uma evolução do cenário nacional, política fiscal em harmonia com o ordenamento econômico e financeiro, visando o cumprimento do disposto no texto constitucional. O método de abordagem utilizado foi o dedutivo, combinado com a pesquisa bibliográfica.
\end{abstract}

Palavras-chave: Justiça Social. Desenvolvimento Nacional. Política Fiscal.

\section{INTRODUÇÃ̃O}

\footnotetext{
${ }^{31}$ Mestranda em Direito pela Universidade de Marília (UNIMAR). Pós-graduada em Direito Civil e Processo Civil pela Universidade Católica Dom Bosco. Professora da Universidade Luterana do Brasil (ILES/ULBRA).

${ }^{32}$ Doutora em Educação (Política e Gestão) pela Universidade Metodista de Piracicaba (UNIMEP). Mestre em Economia (Política) pela Pontifícia Universidade Católica de São Paulo (PUC-SP). Docente do Programa de Mestrado e Doutorado em Direito da (UNIMAR).
} 
Neste trabalho será abordado o tema "Políticas Fiscais Como Instrumento de Redução da Desigualdade Social”, tem-se como problemática: as políticas fiscais podem ser efetivas na redução das desigualdades sociais?

Com fundamento neste questionamento, a pesquisa tem como objetivo geral fazer uma análise acerca das políticas sociais através da implantação de políticas fiscais e monetárias. E ainda, tem como objetivos específicos: analisar o modo de produção capitalista e os desafios do Estado Democrático de Direito, abordar a implementação de políticas sociais através das políticas públicas, bem como a utilização da Política Fiscal, por meio da tributação, como instrumento hábil para correção das desigualdades nacionais. Referenciar a importância da utilização da política fiscal conjuntamente com o ordenamento econômico e financeiro com vistas ao desenvolvimento econômico e social.

O trabalho é bibliográfico, para tanto, utilizar-se-á o método dedutivo, tendo como foco o disposto nos textos legais, bem como nos posicionamentos doutrinários que envolvam o tema, abrangendo bibliografias encontradas em domínio público como: livros, revistas, monografias, teses, entre outras.

\section{MODELO DE PRODUÇÃo CAPITALISTA E A MÁ REPARTIÇÃo DE RENDA NO BRASIL: DESAFIOS DO ESTADO DEMOCRÁTICO DE DIREITO}

Para compreensão do modelo capitalista na atualidade é necessário adentrar em uma análise referente às questões históricas, até as origens atuais da economia de mercado tal como impostas de forma global pelo capitalismo.

O capitalismo como sistema econômico, político e social desenvolveu-se vagarosamente há vários séculos, primeiramente na Europa Ocidental e, posteriormente, em extensões maiores e de forma globalizada. Ao passo que com o aumento de suas dimensões, surgia também à necessidade de compreensão desse sistema (HUNT, 2005, p. 1).

Concepção que perpassa pelo declínio do feudalismo na Europa Ocidental, o qual já havia atingido e ultrapassado seu potencial econômico, e que foi antecipado, posteriormente, pelo comércio, ocasionando consequentemente a sua dissolução. Segundo Hunt

a expansão do comércio, particularmente de longa distância, levou ao estabelecimento de cidades industriais e comerciais para servir a esse comércio. $\mathrm{O}$ crescimento dessas cidades, bem como o seu crescente controle por capitalistas 
comerciantes, provocou importantes mudanças, tanto na agricultura quanto na indústria. Cada uma dessas áreas, particularmente a agricultura, teve enfraquecidos e, por fim, rompidos seus laços com estrutura econômica e social feudal (HUNT, 2005, p.10).

Naquele contexto, a realeza promovia a política mercantilista, intervia na economia e subsidiava as primeiras empresas capitalistas, incitando a indústria e protegendo os frutos do trabalho burguês ou sua capacidade de exploração, e com isso atenuava e encobria a agudeza da contradição frontal que era um governo de reis e nobres. A base econômica da sociedade se alterara profundamente, gravitando já o poder da riqueza noutro reino social de todo distinto, qual seja o da burguesia recém-formada e fortalecida (BONAVIDES, 1980, p.91).

Neste sentido Bonavides (1980), já afirmava que o capitalismo nasceu intervencionista e há de morrer monopolista, para o autor o interesse por imposição do capitalismo já se fazia presente no pensamento burguês, quando estes acolhiam a política cordial advinda da realeza, poder político que era infesto, que continuava desfrutando privilégios e vantagens sociais, isto, para confirmar que a economia capitalista, cresceu amparada nos braços do Estado, protegido desde o berço pela política dos príncipes, cuja intervenção no domínio econômico se processa sempre em ordem a sustentar o empresário débil e desajudado, por isso a burguesia resignava-se. Assim, segundo Hunt (2005, p. 43)

\begin{abstract}
o crescimento das cidades transformou a agricultura rural e criou o estágio comercial da sociedade, o capitalismo, criando mercados nos quais os senhores feudais podiam trocar seu excedente agrícola por produtos industrializados. O desejo de obter produtos industrializados levou aos movimentos de cerceamentos. Isso ocorreu, segundo Smith, porque a agricultura medieval era muito ineficiente. A vontade de comprar mais produtos levou os senhores a aumentar a eficiência, mandando embora os colonos desnecessários e diminuindo o número de trabalhadores da terra ao número necessário para cultivá-la, de acordo com o estado imperfeito de cultivo e os progressos daquela época.
\end{abstract}

Sobretudo, e em vista das considerações expostas, é que a maioria dos economistas define o capitalismo como um sistema econômico que se baseia no modo de produção, ou seja, pelas forças produtivas, denominadas tecnologia produtiva de uma sociedade, conjuntamente com os arranjos sociais através dos quais uma classe une suas forças produtivas para produzir todos os bens, inclusive o excedente, enquanto a outra parte apenas apropria-se.

Segundo Hunt (2005, p. 1) o capitalismo é caracterizado por

quatro conjuntos de arranjos institucionais e comportamentais: produção de mercadorias, orientadas para o mercado; propriedade privada dos meios de produção; um grande segmento da população que não pode existir, a não ser que venda sua força de trabalho no mercado; e comportamento individualista, aquisitivo, maximizador, da maioria dos indivíduos dentro do sistema econômico. 
Com fundamento nas definições acima expostas, observa-se, que a maior parte dos indivíduos, nas diversas sociedades, labora de forma incessante e exaustiva na ânsia de produzir o imprescindível para amparar e eternizar-se o modo de produção, bem como o excedente social, enquanto uma parte menos numerosa toma posse do excedente e o domina. Não obstante, resta claro que a propriedade dos meios de produção, fundamento do capitalismo, tornou o capitalista a classe predominante desde o seu princípio.

Neste sentido, Adam Smith dizia que em uma sociedade capitalista diferentes condições de propriedade eram, uma vez mais, a base das grandes divisões de classes. A propriedade determinava a fonte de renda de um indivíduo e consequentemente era o principal determinante de qual classe social o indivíduo pertencia (HUNT, 2005, p.44).

Afora os já citados, outros fatores contribuíram na passagem para o capitalismo, entre eles cita-se o despertar intelectual do século XVI, que originou o processo científico e consequentemente na prática da navegação (HUNT, 2005). Bem como a passagem do final do século XVI e início do século XVIII, em que as grandes cidades da Inglaterra, França e Espanha, Bélgica e Holanda, já tinham se transformado em bem-sucedidas economias capitalistas, dominadas pelos mercadores capitalistas que controlavam não só o comércio, mas também, a indústria, época conhecida como mercantilismo.

Indubitavelmente, um importante fator que marca a compreensão do modelo capitalista é a criação da máquina a vapor, por James Watt, em 1769, e sua utilização nos processos industriais e consequentemente seu emprego na geração de trabalho, alterou-se consideravelmente o arcabouço social e comercial da época. Nesse período de expansão comercial ao final da Idade Média, a sociedade percebia uma dinâmica diferenciada nas relações de produções e social; de uma produção incipiente, artesanal, cujo produtor tinha consciência de seu trabalho e seu produto com a consequente oneração sobre o mesmo, o período vivenciou a expansão da produção em massa beneficiada pela máquina a vapor. Dito período foi denominado de Revolução Industrial, iniciado na Inglaterra no século XVIII, propagando-se por todos os continentes (PINTO, 2010).

A partir daí, o trabalhador já não tinha mais a consciência do seu trabalho e do resultado deste, não podendo determinar o preço sobre a mercadoria, sendo obrigado a vender a sua força de trabalho para o capitalista que, desde o início, percebeu que o trabalho humano cria valor sobre a matéria prima, transformando-a em capital de lucro.

É o que assinala o pensamento de Karl Marx sobre o modelo capitalista 
uma relação sui generis que se caracteriza pela compra e venda da força de trabalho e que só se tornou possível sob determinadas condições e visando determinados fins que ficarão mais claros depois. Em outras palavras, o capitalismo surge quando tudo se torna mercadoria, inclusive a força de trabalho. Para que isto ocorra é necessário que uma classe (a burguesia) se torne proprietária exclusiva dos meios de produção e que outra (o proletariado), não tendo mais como produzir o necessário para sobreviver, seja obrigada a vender no mercado sua força de trabalho (HUNT, 2005, p. 54).

De certa maneira, foi à ruptura moderna com o espectro de mundo que dava sustento ao Antigo Regime, entre outras coisas, que se modificou a expectativa de visão em relação ao outro. Mas, não foi só essa ruptura de visão de mundo que contribuiu com o advento do capitalismo e a noção de direitos e garantias do homem. A Revolução Industrial que necessitava de regulamentação sobre o trabalho e a Declaração dos Direitos do Homem e do Cidadão, durante a Revolução Francesa, em 1789, que reconheceu a liberdade e a igualdade universalmente a todos os homens e tornou aceitável a participação de cada indivíduo nas deliberações e ações comuns a todos, tiveram papel fundamental para esse novo paradigma.

Em vista disso, importa mencionar que a Revolução Industrial trouxe diversas consequências para a Inglaterra, entre elas a urbanização exacerbada, o crescimento da taxa de natalidade, a mutação na consciência política e social, as primeiras medidas de política social (VIEIRA, 2009). Consequência essa que se repetiu em outros países, acarretando os problemas idênticos ao da Inglaterra.

Percebe-se, então, uma crise econômica e política desenvolvida por esses movimentos e que posteriormente desencadeou, em 1830, na crise decisiva tanto na França quanto na Inglaterra em que a burguesia apoderou-se do poder político, gerando consequentemente uma luta de classes. Estabelecia-se, definitivamente, interesses opostos de classes sociais: de um lado o trabalhador e de outro o capitalista, dono dos meios de produção. Pode-se, então, afirmar que os ideais capitalistas sempre foram à concentração de riqueza nas mãos daqueles que detinham o poder e noutro ponto uma grande maioria privados de quaisquer recursos, desigualdades sociais e dominação de classes sobre outras.

Não obstante, as alterações sofridas no contexto global, a partir da década de 1960, manifestaram-se indícios de esgotamento e da ampliação dos processos de modernização capitalista no ocidente. O que desencadeou o declínio das taxas de lucro dos grandes monopólios transnacionais, a redução do crescimento econômico nas principais economias capitalistas e o crescente déficit fiscal dos Estados, denunciava-se, portanto, o fim da Era de Ouro do Capital (SOUZA, OLIVEIRA, 2011).

Por conseguinte, é possível inferir que foi um período de uma maior especificação e divisão do trabalho, caracterizado com uma constante redução das operações de produção, 
sempre voltadas para um aumento na produtividade e no controle da referida produção. Uma mudança de estrutura e de comportamento do indivíduo, e da própria sociedade. O que acarretou um aumento considerável de desempregados, e que desencadeou na crescente inutilização da força laboral humana.

Justamente nesse período que os chamados economistas liberais James Mill, David Ricardo e Adam Smith, iriam sustentar a tese de que a atividade econômica devia se afastar da influência do Estado, tornando a livre concorrência o postulado principal do liberalismo econômico que viria prevalecer até os dias de hoje (PINTO, 2010).

É nessa perspectiva que Santos menciona sobre a mudança de paradigma,

\begin{abstract}
No final do século XIX, o panorama jurídico e político alterou-se dramaticamente, sobretudo devido ao crescente domínio do modo de produção capitalista, não só sobre as relações econômicas, mas também em todos os aspectos da vida social. A concentração e centralização do capital industrial, comercial e financeiro, a proliferação de cartéis e monopólios, e a separação entre propriedade jurídica e controle econômico ilustraram a extraordinária expansão do princípio do mercado, ao mesmo tempo que puseram fim ao mercado competitivo e auto-equilibrável (SANTOS, 2011, p. 147-148).
\end{abstract}

Desse modo, na visão de Boaventura de Sousa, o capitalismo está mais organizado do que nunca esteve na história, domina atualmente todos os aspectos da vida social, e ainda, neutralizou todos os inimigos tradicionais como o movimento socialista, o ativismo operário e as relações sociais não-mercantilizadas (SANTOS, 2011).

Note-se, portanto, que a ampliação espetaculosa dos mercados mundiais, bem como a crescente inovação nos processos de produções em sentido global, bem como as grandes corporações transnacionais e multinacionais, desgastaram e prejudicaram a disposição do Estado para satisfazer o mercado interno, ou seja, o nacional.

Por outro lado, a economia de mercado, não exerceu seu compromisso de assegurar um sistema de trocas admissíveis, e nem tampouco oportunidade de competitividade igualitária. Os modelos econômicos que se afrontaram no século XX não ofereceram recursos para uma sociedade justa e solidária, o capitalismo comprovou saber lançar riquezas, mas não conseguiu distribuí-la, já o comunismo evidenciou saber difundi-la, mas não conseguiu produzi-la.

De fato, a disparidade no palco econômico provém da circunstância desproporcional dos cidadãos em face do mercado, os que possuem capitais não precisam ceder sua força de trabalho, ao passo que os que são desprovidos de capital cedem a sua força laboral, aliena sua força de trabalho para sua própria subsistência, encarando, de frente o mercado capitalista. 
Fato é que o século XX não findou bem. Existe uma grande centralização de renda nas mãos de poucos, por conseguinte, as dificuldades sociais são de extensões enormes, com disparidades exasperadas e com sérios problemas ambientais. Por força, disso, que Giddens (2007) cita com propriedade que "em consequência do desenvolvimento industrial global, talvez tenhamos alterado o clima do mundo, além de ter danificado uma parte muito maior de nosso habitat terrestre".

O capitalismo em sua forma monopolizada acresce cada vez mais o capital e as expectativas de lucratividade, limitando e obstruindo a concorrência, ao invés de investir e aperfeiçoar a produção que já existe no mercado, preservando a todo custo a lei do mercado e bases capitalistas.

É nesse contexto que o século XXI carreou todos esses problemas e ainda desenvolveu novos; nos dizeres de Amartya Sen "nunca foram tão acentuadas as desigualdades e as privações, para um grande contingente da população mundial” (SEM, 2000, p. 29).

De certa maneira, o mundo global traz transformações e gera efeitos em praticamente todos os aspectos da vida - positivos e negativos, que não podem ser ignoradas para a análise da sociedade atual. Há que se visualizar o fenômeno para além dos termos econômicos (SANTIAGO, CAMPELLO, 2015), a exemplo da própria condição humana sobre o aspecto psicofísico e emocional.

Por conseguinte, essas alterações não encontram limites e muitas vezes acarretam desajustes na sociedade, no meio ambiente, no modo de agir e pensar dos seres humanos, já que ficam todos intrinsecamente dependentes do modelo de produção capitalista e suscetíveis com as oscilações que afetam a vida das pessoas. Com uma produção e uma comunicação mais rápida, não há mais que se falar em segurança, mais em uma instabilidade jurídica e econômica que interferem na vida de milhares de pessoas. A sedimentar esse raciocínio, vale mencionar Ferrajoli:

A crescente interdependência econômica, política e ecológica e cultural realmente transformaram o mundo, apesar do aumento de sua complexidade e de seus inúmeros conflitos e desequilíbrios, numa aldeia global. Hoje, graças à rapidez das comunicações, nenhum acontecimento no mundo nos é alheio e nenhuma parte do mundo nos é estranha (FERRAJOLI, 2002, p. 47).

$\mathrm{Na}$ contemporaneidade, ainda que se presencie a consolidação de um modelo globalizado do capitalismo este tem provocado consequências desastrosas mundo afora, surgindo cada vez mais um número indeterminado de desempregados e sem nenhuma chance de inserção nos modelos de representação do modo capitalista, surgindo na contemporaneidade a ampliação do pensamento neoliberalista, o que acarretou 
concomitantemente uma maior desigualdade social, um afastamento entre riqueza e pobreza que se manifesta a nível mundial.

Em virtude desta dinâmica, são percebidos o aumento de número de desabrigado, da criminalidade e a criação de "bolsões de miséria", como no Brasil, tornam-se cada vez mais constantes no capitalismo global (SOUZA, OLIVEIRA, 2011), fenômenos típicos de sociedades periféricas.

No entanto, no Brasil, especificamente, o sistema capitalista deparou-se no modo de desenvolvimento que assegurava tão-somente o acúmulo de capitais das transnacionais em conjunto com a sociedade burguesa. Tal circunstância acarretou, na década de 1970, a falência do processo de modernização brasileira, juntamente com a crise globalizada e as taxas elevadas de crescimento econômico, o que acabou por retroceder e limitar a modernização. Neste período, o Brasil vivia a Ditadura Militar com supressão de direitos e a busca por um desenvolvimento nacional sem precedentes a, qualquer preço e ônus para a sociedade.

Consequentemente, houve o colapso do desenvolvimento no Brasil que acarretou uma crise de cunho duradouro, ocasionando aumento de desempregados, a criação de novas favelas e o aumento da criminalidade, dentre outros problemas. Nesse sentido, dispõe Sousa e Oliveira que:

\footnotetext{
Os desdobramentos sociopolíticos imediatos à crise da modenização capitalista no Brasil expressos, na sua superficialidade, no fim do "Milagre Econômico", foram mediados pelas peculiaridades do seu processo político-institucional, sobretudo durante a década de 1980. A Ditadura Militar foi responsável pela consolidação do processo de modernização do país. Desse modo, como desdobramento da industrialização-urbanização, houve uma complexificação da sociedade brasileira em que diferentes classes e grupos sociais passaram a empreender atividades ideopolíticas e culturais resultando na expansão e amadurecimento da sociedade civil (SOUZA, OLIVEIRA, 2011, p. 133).
}

Desse modo, este contexto teve como marco uma política divergente entre a política econômica imposta na sociedade civil aliada à impossibilidade de participação política que a ditadura impunha. O desempenho político das classes médias bem como da classe trabalhadora, com a criação de partidos políticos, sindicatos, as organizações e movimentos populares, instigaram os questionamentos em relação ao desenvolvimento representado pela era da ditadura. A partir dessas alterações e com a crise econômica surgida nos anos 1980, foram surgindo projetos econômico-políticos de forma alternativa, envolvendo a população e classe política, surgindo, em ato contínuo as concepções neoliberais. 
Frise-se que na esteira dos ideais neoliberalistas, a crise econômica dar-se-á em razão do exagero de regulamentação e intervenção econômica do Estado, o que necessitaria uma redução da participação ativa do Estado brasileiro, levando posteriormente a privatização de empresas estatais na década de 1990. Importa ressaltar que esta privatização das estatais e redução de alguns direitos de cidadãos brasileiros seguiu uma linha de orientação de fundos investimentos internacionais, a exemplo do Fundo Monetário Internacional - FMI, que obrigou o país a adotar medidas de contenção de despesas e redução de direitos a fim de cumprir os seus compromissos financeiros junto às instituições de créditos, mesmo o Brasil vivendo o período da Constituição de 1988, que promoveu a redemocratização na sociedade brasileira.

Por outro lado, note-se, que a compreensão de Estado Democrático, fundada na soberania de todo um povo composto por homens e mulheres livres e iguais, é relativamente hodierna na história humana e um desafio constante para as sociedades que se querem consolidar democráticas.

Desse modo, apesar das pesadas imposições pelas instituições financeiras, a sociedade brasileira lutou pela garantia e apropriação dos ideais sociais e políticos, com o implemento de projetos socioeconômicos, com bases democráticas, ainda que atualmente sejam incipientes, o que pode-se ser notado em face das contradições existentes na atualidade, entre pobres e ricos, desempregos, criminalidade, etc.

De fato, no Brasil, assim como nos demais países periféricos, esses territórios, denominados "zona cinzenta" jamais deixaram de fazer parte do espaço urbano no contexto da modernização do país. A modernização capitalista no Brasil não estabeleceu formas de integração efetiva das populações dessas áreas a partir de estratégias redistributivas (SOUZA, OLIVEIRA, 2011). Há, portanto, um grande contingente de indivíduos sobrando em face das necessidades de acúmulo e produção de capitais.

Diante desse paradigma, pode-se afirmar que no atual contexto político-econômico brasileiro, a política fiscal será essencial para a criação de políticas públicas para alterar esse cenário de miserabilidade de determinadas regiões, através de medidas aptas a propiciar o desenvolvimento em todas as áreas, para que os indivíduos possam ter sua dignidade preservada e com possibilidade de uma melhor qualidade de vida em cumprimento a justiça social.

Por derradeiro, faz-se necessário o empenho no desenvolvimento de planos de ações para gerir as dificuldades oriundos da implementação do capitalismo exacerbado, bem como uma maior efetivação das políticas fiscais voltadas para projetos de uma melhor redistribuição 
da arrecadação tributária, com fito de fomentar e alavancar políticas públicas articuladas para desenvolvimento de regiões esquecidas no contexto nacional. Uma forma de o Estado cumprir com o disposto no texto constitucional, de possibilitar uma vida digna aos cidadãos.

\section{A POLÍTICA FISCAL BRASILEIRA E O PARADIGMA DA JUSTIÇA SOCIAL}

Num Estado Democrático de Direito, como o Brasil, incidem sobre as bases governamentais desempenhos específicos e de suma importância, como exemplo a organização e destinação das verbas públicas, bem como a execução e o desenvolvimento da Administração dos bens públicos, assim como emprego e o projeto de atos em prol da coletividade, abrangendo vários setores, o que se dará através de Políticas Públicas que permitem além da idealização, o cumprimento ordenado dessas ações. Nesse ponto, Bucci define Políticas Públicas como:

\footnotetext{
Política Pública é o programa de ação governamental que resulta de um processo ou conjunto de processos juridicamente regulados - processo eleitoral, processo de planejamento, processo de governo, processo orçamentário, processo legislativo, processo administrativo, processo judicial - visando coordenar os meios à disposição do Estado e as atividades privadas, para a realização de objetivos socialmente relevantes e politicamente determinados. Como tipo ideal, a política pública deve visar a realização de objetivos definidos, expressando a seleção de prioridades, a reserva de meios necessários à sua consecução e o intervalo de tempo em que se espera o atingimento dos resultados (BUCCI, 2006, p. 39).
}

Ao se interpretar a lição acima, tem-se claro que assim como as Políticas Públicas é necessário, em contexto de países em desenvolvimento, de programas de ações governamentais aptas para uma efetiva Administração Pública, neste sentido, a Política Fiscal, exerce papel correlato, eis que é através dela que o Estado consegue angariar receitas públicas para desenvolver suas funções inerentes, bem como organizar e executar as Políticas Públicas.

Pode-se dizer que dada à importância das Políticas Públicas no cumprimento das ações governamentais, o Texto Constitucional de 1988 adotou, entre outros, o conceito de política pública e social, abrindo um espaço no seu texto normativo e determinando que fosse atribuída essa finalidade na seara da política fiscal, visto a importância desta para a sociedade brasileira.

Sendo assim, num contexto econômico, as políticas monetárias bem como as políticas fiscais são decisivas para o desenvolvimento da economia. Segundo a teoria Keynesiana a política monetária é importante, em determinadas circunstâncias, principalmente na 
determinação das taxas de juros, ao passo que a política fiscal compõe-se de uma sucessão de fatores relativos à tributação, entre eles aumento ou diminuição de impostos e os gastos governamentais (KEYNES, 1982).

Como consequência, tem-se a importância de uma política fiscal, especificamente a tributária, em uma sociedade, principalmente pelo fato de ser esta a responsável por implementar programas jurídicos e sociais tanto na política quanto na economia. O que pressupõe a tributação atuando em mais frentes que não só as voltadas para induzir comportamentos, mas como ferramenta de redistribuição de renda, que permite o fortalecimento da sociedade (VITTA, 2011).

Assim, para uma compreensão da interface entre economia e política fiscal, é imprescindível, refletir sobre as situações em que o mercado econômico se encontra em níveis desacelerados, com crescentes níveis de desempregos, diminuição dos lucros e consequentemente redução de investimentos. É justamente nesses contextos de crises que Keynes aponta que "para aumentar seus gastos, o governo terá de aumentar seus recursos, aumentando os impostos ou contraindo dívidas (aumentando os déficits orçamentários)" (KEYNES, 1982, p.132), ou seja, instituindo políticas fiscais.

Ainda assim, pode-se afirmar que as políticas fiscais são medidas adotadas pelo governo com intuito de sobrepujar momentos de instabilidades ocorridas no mercado econômico como um todo, ou seja, possibilidades de surgimento de um ambiente propício ao desenvolvimento econômico.

Sobretudo, quando se verifica em uma sociedade o desarranjo entre um número excedente de pobres e um número inferior de ricos, em que o Estado tenta equilibrar essa disparidade por meio da cessão de capitais da minoria para a maior parte dos menos favorecidos, através de uma política fiscal.

Nesse contexto, que Keynes assinalava duas grandes fraquezas do sistema capitalista: o desemprego e a distribuição excessivamente desigual e arbitrária de renda e da riqueza. Por isso, a teoria keynesiana foi uma revolução na teoria econômica, abriu espaço para uma revolução política econômica, ou seja, a intervenção do Estado na economia (KEYNES, 1982).

De fato, o intervencionismo estatal é um acontecimento relativo ao exercício de uma sistematização por parte do ente estatal sobre a economia. Ou seja, a ação do Estado no domínio econômico, buscando, no exercício de suas funções, alcançar determinados fins. Atua no campo da atividade econômica, incidindo tanto no exercício de atos materiais, como na produção de atos normativos (GRAU, 2008). 
Em contraponto ao intervencionismo, é oportuno mencionar que a partir do momento que o texto constitucional prevê os direitos fundamentais e os asseguram, impossibilita o excesso do Estado na elaboração de políticas fiscais, o que se dará através dos princípios que demarcam a ação do Estado. A título de complementação pode-se afirmar que entre as políticas fiscais, a tributária é o processo que deve anteceder a imposição tributária, ou seja, a verificação da finalidade pela qual será efetivada ou não a imposição tributária (VINHA, RIBEIRO, 2005).

Entretanto, apesar da política fiscal, por meio da tributação, ser a ferramenta apropriada para a arrecadação, não necessariamente resultará tão-somente em comandos imperativos. O Estado poderá realizar esta política por meio de benefícios fiscais como, por exemplo, o incentivo fiscal, a isenção, alíquota zero, dentre outros, como forma de reprimir aumentos e até a constância na tarefa arrecadatória, momento em que a política fiscal terá caráter não apenas fiscal, mas também extrafiscal, contribuindo na redução das desigualdades. Nesse sentido, escreve Regina Helena Costa que,

Fiscalidade traduz a exigência de tributos com o objetivo de abastecimento dos cofres públicos, sem que outros interesses interfiram no direcionamento da atividade impositiva. Significa olhar para o tributo, simplesmente, como ferramenta de arrecadação, meio de geração de receita. A extrafiscalidade, por sua vez, consiste no emprego de instrumentos tributários para o atingimento de finalidades não arrecadatórias, mas, sim, incentivadoras ou inibitórias de comportamentos, com vista à realização de outros valores, constitucionalmente contemplados (COSTA, 2009, p. 48).

Percebe-se, assim, que a conotação dada à tributação pela Constituição Federal de 1988 não se verifica, fundamentalmente, pela invasão patrimonial do cidadão, obrigando-o ao pagamento arbitrário de tributos, mas antes, prevê que esta colaboração do particular com as ações estatais para a promoção do bem-estar da coletividade, da organização do Estado e de suas estruturas passa a ser a partir dos fundamentos constitucionais que limitam este poder estatal, através das garantias fundamentais. Paulo de Barros Carvalho esclarece que:

Fala-se em fiscalidade sempre que a organização jurídica do tributo denuncie que os objetivos que presidiram a sua instituição, ou que governam certos aspectos da sua estrutura estejam voltados ao fim exclusivo de abastecer os cofres públicos, sem que outros interesses - sociais, políticos ou econômicos - interfiram no direcionamento da atividade impositiva. A experiência jurídica nos mostra, porém, que vezes sem conta a compostura da legislação de um tributo vem pontilhada de inequívocas providencias no sentido de prestigiar certas situações, tidas como social, politica ou economicamente valiosas, às quais o legislador dispensa tratamento mais confortável ou menos gravoso. A essa forma de manejar elementos jurídicos usados na configuração dos tributos, perseguindo objetivos alheiros aos meramente arrecadatórios, dá-se o nome de extrafiscalidade (CARVALHO, 2009, p. 254-255). 
$\mathrm{Na}$ mesma linha da importância de uma arrecadação que vislumbre mais que uma invasão patrimonial por si mesma, o autor corrobora a importância de se utilizar os institutos do direito para garantir que a obrigação tributária seja uma forma de garantir direitos. Nesse sentido, ensina Nabais sobre a natureza fiscal do Estado contemporâneo,

\footnotetext{
Olhando para o suporte financeiro do estado contemporâneo, o que vemos é um estado fiscal, um estado que tem nos impostos o seu principal suporte financeiro. $\mathrm{O}$ que, atenta a razão de ser do estado, que á a realização da dignidade da pessoa humana, o estado fiscal não pode deixar de se configurar como um instrumento, porventura o instrumento que historicamente se revelou mais adequado à materialização desse desiderato (NABAIS, 2017).
}

Nessa linha de pensamento, pode-se assegurar que, política fiscal, por meio dos tributos, é um custo que todos os contribuintes aptos deverão pagar a um determinado estado moderno para que este, consequentemente, efetive uma sociedade organizada, com enfoque em uma justiça social. Por outro lado, ele é receita para a promoção de ações que impliquem na concretização dos objetivos fundamentais da República Federativa do Brasil.

\section{JUSTIÇA SOCIAL COMO PRESSUPOSTO DA POLÍTICA FISCAL: APLICAÇÃO DO ARTIGO 170 DA CF/88 NA REDUÇÃO DA DESIGUALDADE ECONÔMICA E SOCIAL}

A Constituição Federal de 1988 apresenta como fundamento do Estado Democrático de Direito os chamados Objetivos Fundamentais da República Federativa do Brasil, expressos no art. $3^{\circ}$, o qual prescreve como objetivos: construir uma sociedade livre, justa e solidária; garantir o desenvolvimento nacional; erradicação da pobreza, marginalização e redução das desigualdades sociais e regionais, entre outros.

Acompanhando esse pensamento, cabe lembrar que para que o Estado possa promover a redução das desigualdades sociais e regionais, bem como o desenvolvimento nacional, como objetivo fundamental do Estado Democrático Brasileiro, faz-se necessário além de recursos financeiros, promover o disposto no art. 170 do Texto Constitucional, que versa sobre os Princípios Gerais da Atividade Econômica.

Assim, os referidos princípios não constituem somente a base da ordem econômica, alguns deles, são norteadores do próprio sistema jurídico constitucional. É dizer, seguramente, que daí decorre a importância da ordem econômica e financeira no desenvolvimento nacional e na redução das desigualdades econômicas e regionais. Nesta linha de pensamento, assegura 
Eros Grau que "a ordem econômica mencionada no art. 170, caput do texto constitucional deve ser dinamizada tendo em vista a promoção da existência digna de que todos devem gozar" (GRAU, 1988, p. 196).

De fato, a ordem econômica precisa estar sustentada nos objetivos fundamentais da República Federativa do Brasil, bem como nos princípios constitucionais que a discriminam, consoante o art. 170 da Carta Magna, devendo o Estado buscá-los incessantemente.

Posto isso, como já dito, para que o Estado possa promover e efetivar os objetivos fundamentais previstos no Texto Constitucional, bem como, cumprir os princípios gerais da atividade econômica, entre eles reduzir as desigualdades econômicas e sociais, necessita de recursos financeiros, já que ele não o produz.

Para tanto, sabe-se que a Administração Pública, na gestão dos bens da sociedade, possui despesas e, para supri-las é preciso, que Ele obtenha recursos financeiros e, para tal intento, o Poder Público desenvolveu mecanismos para a aquisição destes recursos. Excepcionalmente, Ele pode exercer atividades econômicas por motivos de segurança nacional ou de relevante interesse coletivo no sentido de obtenção de recursos para suas finalidades.

Por outro lado, o Estado também pode utilizar de seu Poder de Império e utilizar sua coercitividade para impor às pessoas à obrigação de pagar tributos, sendo esta considerada uma receita pública derivada, já que geralmente, provém de bens e patrimônio de particulares que são obrigados a retirar parcela de suas riquezas para a satisfação creditícia do ente Estatal.

Assim, como forma imediata de angariar recursos, o Estado utiliza da política fiscal, arrecadação de tributos, para conseguir solver essas despesas públicas. Portanto, a política fiscal, por meio do tributo é um importante instrumento pelo qual o Estado pode utilizar para realizar seus fins previstos constitucionalmente, entre eles a redução das desigualdades sociais e regionais.

Nesta esteira, Hugo de Brito cita que a atividade tributária é o instrumento de que se pode valer o Estado na luta pelo desenvolvimento em seus três aspectos fundamentais, a saber, o econômico, o social e o político (MACHADO, 1987). Justamente para desenvolver os aspectos econômicos, sociais e políticos é que o Estado depende dos recursos oriundos das receitas tributárias para desenvolver suas atividades, bem como assegurar a defesa, manter a paz e a ordem interna e, concomitantemente, fomentar as políticas públicas voltadas ao desenvolvimento nacional, e, por conseguinte, atuar para minimizar as desigualdades entre as regiões e entre as pessoas. 
De certa maneira, na implementação das políticas fiscais, há obtenção de recursos públicos, para tanto, o Estado deve se estruturar como uma organização, desenvolvendo atividades financeiras como o fito de arrecadar fundos, dando equilíbrio às receitas e despesas através do planejamento orçamentário (DOMINGOS, CUNHA, 2017).

Com efeito, o Estado tem o condão de tratar com a mesma importância a receita tributária, bem como a sua devida e adequada utilização, vez que é através da destinação e aplicação dos valores arrecadados por meio destas que o Estado utilizará para promover a dignidade dos cidadãos e propiciar meios para o desenvolvimento nacional, bem como, buscar reduzir as desigualdades econômicas e sociais.

É nesse sentido, que contemporaneamente, a política fiscal, por meio da arrecadação de impostos, não é mais vista apenas como instrumento de angariar recursos para os cofres públicos, mas como um instrumento de política e atuação estatal em diversas áreas, sobretudo na social e na econômica (RIBEIRO, 2013).

Para tanto, a implantação de política fiscal relativas à tributação, demanda obrigatoriamente esforço para reduzir as desigualdades econômicas e sociais. Desse modo, o Estado, ao comprometer-se a respeitar o princípio fundamental da dignidade da pessoa humana, deve direcionar-se e avançar no sentido de promover o desenvolvimento nacional como um todo, implantando políticas públicas hábeis à concretização do bem comum. Trabalhando em sentido contrário ao agrupamento de rendas, a exclusão social, a miserabilidade, dentre outros fenômenos que desprezam e desvalorizam a dignidade da pessoa humana.

Por esse motivo, a política fiscal, por meio da tributação deve ser compreendida como um instrumento que auxilia na correção de desajustes e diminuição das desigualdades, bem como dá amparo ao crescimento e ao desenvolvimento nacional em todos os seus aspectos, uma vez que importa também como elemento que regula a atividade econômica e social. Por conseguinte, a justa repartição do total da carga tributária entre os cidadãos é imperativo ético para o Estado Democrático de Direito (RIEIRO, 2013).

A partir desse encadeamento de ideias é possível concluir que, a política fiscal tributária deve estar em harmonia com o ordenamento econômico e financeiro, com as propostas e metas de desenvolvimento nacional, visando à mesma finalidade: satisfação das necessidades da população e o desenvolvimento econômico social (RIBEIRO, 2013). A propósito é um dever e direito do Estado exigir tributo, desde que observado os ditames legais e respeitados os direitos dos contribuintes em harmonia com o princípio da dignidade da pessoa humana em face da redução das desigualdades econômicas e sociais. 
Por derradeiro, importa mencionar que não basta o Estado exercer o seu direito subjetivo de planejar políticas fiscais, como a cobrança do tributo, e o particular o seu dever jurídico ao pagamento do tributo, ainda que de acordo com a Lei; é preciso que o Estado atente para as diferenças sociais e econômicas que o modelo de produção capitalista adotado pelo Brasil submete os seus cidadãos, que se caracteriza por ser um modelo excludente e de má distribuição de renda, situação que se vê constantemente noticiada e denunciada nos Poderes Públicos e nos meios de comunicação.

\section{CONSIDERAÇÕES FINAIS}

As políticas sociais desempenham um importante papel no desenvolvimento nacional, através das políticas monetárias bem como das fiscais, tendo o compromisso de implantar programas sociais e econômicos, uma vez que através das políticas públicas o Estado propicia o desenvolvimento social e econômico.

Constata-se que, mesmo em uma economia de mercado globalizada, muitas vezes desigual e não contínua, com constantes desafios do modo capitalista de produção, que tem o lucro e acumulação de riqueza como fator predominante, é ainda possível que o Estado desenvolva políticas fiscais, por meio da tributação, de forma a propiciar o desenvolvimento econômico e social.

Neste contexto, resta evidente que o interesse do Estado ao implantar políticas fiscais tributárias é harmonizar-se com o ordenamento econômico e financeiro, consequentemente, perquirir para o alcance da justiça social. Contudo, o papel desempenhado pela implantação de políticas fiscais, deverá ir além, ou seja, não somente desenvolver suas funções precípuas, mas atuar por meio de ações de modo a incrementar o desenvolvimento em todos os seus aspectos.

Dentro do quadro do Estado Democrático de Direito, lastreado nas ideias de participação e desenvolvimento, as políticas fiscais, têm o compromisso de complementar às políticas públicas do Estado, desenvolvendo projetos e ações para o desenvolvimento da sociedade, atuando no desenvolvimento econômico e social.

\section{REFERÊNCIAS}

BONAVIDES, Paulo. A teoria do Estado. 2. ed. Rio de Janeiro: Forense, 1980, p.91. 
BUCCI, Maria Paula Dallari. O conceito de política pública em direito. In: Políticas Públicas. Reflexões sobre o Conceito Jurídico. São Paulo: Saraiva, 2006. p. 39.

COSTA, Regina Helena. Curso de Direito Tributário: Constituição e Código Tributário Nacional. São Paulo: Saraiva. 2009. p. 48

CARVALHO, Paulo de Barros. Curso de direito tributário. 21. ed., São Paulo: Saraiva, 2009. p. 254 e 255.

DOMINGOS. Terezinha de Oliveira; CUNHA. Leandro Reinaldo da. A Tributação como Instrumento de Concretização da Dignidade da Pessoa Humana em Face do Desenvolvimento. Disponível em:

<http://www.publicadireito.com.br/artigos/?cod=154aa6866aefb6f8>Acesso em: 25 jun. 2017.

FERREIRA FILHO, Manoel Gonçalves. Curso de Direito Constitucional. 26 ed. São Paulo: Saraiva, 1999.

FERRAJOLI, Luigi. A soberania no mundo moderno: nascimento e crise do Estado Nacional. Tradução de Carlo Coccioli, Márcio Lauria Filho; Revisão de tradução Karina Jannini. São Paulo: Martins Fontes, 2002.

GRAU, Eros Roberto. A ordem econômica na Constituição Federal de 1988. 10 ed. Malheiros. São Paulo. 2005.

GIDDENS, Anthony. Mundo em descontrole: o que a globalização está fazendo de nós. Tradução de Maria Luiza C. de A. Borges. 6 ed. Rio de Janeiro: Record, 2007.

HUNT. E.K. História do Pensamento Econômico. Tradução José Ricardo Brandão Azevedo, Maria José Cyhlar Monteiro. Revisão técnica de André Villela. Rio de Janeiro: Campus, 2005. p. 1.

KEYNES, John Maynard. A teoria geral do emprego, do juro e da moeda. São Paulo, Atlas, 1982. p. 132

MACHADO, Hugo de Brito. A Função do Tributo nas Ordens Econômica, Social e Política. Revista da Faculdade de Direito. Fortaleza, jul-dez,1987. p.28. 
NABAIS. José Casalta. A face oculta dos direitos fundamentais: os deveres e os custos dos direitos. Disponível em: <http://educacaofiscal.gov.br/wp-content/uploads/2016/11/a-faceoculta-casalta-navais.pdf >. Acesso em: 05 jun. 2017.

RIBEIRO, Maria de Fátima. Considerações sobre as Medidas Fiscais estabelecidas para fazer às crises econômicas e as repercussões no Desenvolvimento Econômico. In: Estudos em Homenagem ao Prof. ALBERTO XAVIER, (org.) Eduardo Paz Ferreira, Heleno Torres e Clotilde C. Palma, vol. II, Editora Almedina, Coimbra, Portugal, 2013, pp. 223-250.

SANTIAGO, Mariana Ribeiro; CAMPELLO, Livia G. Bósio. A Responsabilidade Civil Por Atividade de Risco e o Paradigma da Solidariedade Social. Veredas do Direito, Belo Horizonte, v. 12, n. jan/jun de 2015.

SANTOS, Boaventura de Sousa. A crítica da razão indolente: contra o desperdício da experiência. 8.ed. São Paulo: Cortez, 2011, p. 147-148.

SEGUNDO, Oswalter de Andrade Sena. O Princípio Constitucional da Redução das Desigualdades Regionais e Sociais e Sua Efetivação Jurídico-política na Ordem Econômica. Revista de Direito e Liberdade. Mossoró, v.7, n.3, jul-dez, 2007. pp.371-400.

SEN. Amartya. Desenvolvimento como Liberdade. São Paulo: Companhia das Letras, 2000.

SOUZA, Charles Toniolo de; OLIVEIRA, Bruno José da Cruz. Criminalização dos pobres no contexto da crise do capital: reflexões sobre os seus rebatimentos no Serviço Social. In: Coletânea Direitos Humanos e Serviço Social: polêmicas, debates e embates (org.) Valéria Forti, Cristina Maria Brites. Editora Lumen Juris, Rio de Janeiro. 2011, pág. 113 a 133

Vieira, Evaldo. Os direitos e a política social. 3. ed. São Paulo: Cortez, 2009, p. 189

VINHA, Thiago Degelo e RIBEIRO, Maria de Fátima. Efeitos Sócio-Econômicos dos Tributos e sua Utilização como Instrumento de Políticas Governamentais in TRIBUTAÇÃ O, JUSTIÇA E LIBERDADE. Coord. MarceloPeixoto e Edison Carlos Fernandes, Curitiba: Editora Juruá, Curitiba, 2005.

VITA. Jonathan Barros. Isonomia, Capacidade Contributiva e Direitos Humanos: Nova chave de leitura para a tributação. Anais do XX Congresso Nacional do CONPEDI realizado em Vitória-ES, 16,17, 18 e 19 de nov. 2011, p. 6836. 


\title{
TAX POLICIES AS AN INSTRUMENT FOR THE REDUCTION OF SOCIAL DIVERSITY
}

\begin{abstract}
The purpose of this article is to analyze the forms of contracting with the Government, specifically the Differentiated Regime of Public Procurement, as well as the possibility of using tax incentives for the construction of works related to international mega events, especially the construction of stadiums . It demonstrates in the first moment the possibility of hiring between Public Power and the private initiative, acting jointly in favor of social and economic development. The study seeks to reflect on tax incentives as a stimulus for investments in the construction of large stadiums, through public financing or through tax incentives, through the Differentiated Regime of Public Procurement. In a second moment, it specifically addresses the construction of the Corinthians Arena, in the eastern part of the city of São Paulo. Lastly, as a result of this study, it was concluded that both Arena Corinthians and other works financed by the Public Power together with the private initiative, using the Differentiated Regime of Public Procurement, facilitated in a certain way, bureaucratizing, in another point, Increased the possibility of deviation from purpose, impaired fundamental areas and essential for the promotion of the dignity of the human person.
\end{abstract}

Keywords: Social Justice. National Development. Fiscal policy. 